\title{
Calcifying Nested Epithelial Stromal Tumor of the Liver
}

National Cancer Institute

\section{Source}

National Cancer Institute. Calcifying Nested Epithelial Stromal T umor of the Liver. NCI

Thesaurus. Code C96830.

A rare malignant tumor that arises from the liver and occurs in children. It is characterized by the presence of nested epithelioid and spindle cells. Desmoplasia, calcifications, and bone formation may also be present. 